\title{
Fluorescent Antibody Virus Neutralization Assay
}

National Cancer Institute

\section{Source}

National Cancer Institute. Fluorescent Antibody Virus Neutralization Assay. NCI

Thesaurus. Code C158247.

An immunofluorescence assay method that measures the level of virus-specific neutralizing antibodies in a serum or a plasma sample by the detection of fluorescence in susceptible cells incubated with serial dilutions of the serum/plasma and fluorophoreconjug ated virus. 